Research Article

\title{
Strain Accumulation in Soft Marine Clay due to One-Way Cyclic Load with Variable Confining Pressure
}

\author{
Lei Sun \\ School of Resources and Civil Engineering, Suzhou University, Suzhou 234000, China \\ Correspondence should be addressed to Lei Sun; leisun2015@163.com
}

Received 30 November 2020; Revised 6 March 2021; Accepted 26 March 2021; Published 12 April 2021

Academic Editor: Weerachart Tangchirapat

Copyright () 2021 Lei Sun. This is an open access article distributed under the Creative Commons Attribution License, which permits unrestricted use, distribution, and reproduction in any medium, provided the original work is properly cited.

\begin{abstract}
The effect of variable confining pressure on the strain accumulation in soft marine clay was investigated to gain a better understanding of the deformation characteristic in the subgrade of pavements due to traffic loading. A series of variable confining pressure (VCP) experiments and corresponding constant confining pressure (CCP) experiments were conducted on Wenzhou soft clay using an advanced cyclic triaxial apparatus. A wide range of deviatoric stress amplitudes $\left(q^{\text {ampl }}\right)$, combined with different isotropic stress amplitudes $\left(p^{a m p l}\right)$, and partially drained conditions are simulated in the experiments. The test results indicate that the variable confining pressure significantly influences the permanent axial strain and might exacerbate the potential of subgrade invalidation in soft marine clay area. The normalized permanent axial strain $\left(\varepsilon_{a, 1000}^{p} / \varepsilon_{a, 1000}^{p, C E P}\right)$ after 1000 cycles is logarithmic with the normalized stress path length $\left(L / L_{\mathrm{CCP}}\right)$, and one-unit increment in the amplitude of cyclic confining pressure will induce an increment of $0.0213 \%$ in the permanent axial strain regardless of the CSR values. Based on the data from the CCP tests, a cyclic deviatoric stress ratio threshold is determined to be about 0.7 , which may suggest that the upper bound of criterion will limit the cyclic traffic loadings on soft marine clayey deposit. Finally, the effect of variable confining pressure on the permanent axial strain is quantified and incorporated in a logarithmic model for the subsoil deformation prediction under traffic loading.
\end{abstract}

\section{Introduction}

The rapid development of modern transport infrastructures, such as motorways, railways, and airports, around the southeast-coastal major cities of China has led to the construction of low embankments on thick soft clay ground with poor geotechnical characteristics, namely, with low bearing capacity, low permeability, and high compressibility. When the stress increments induced by long-term repeated traffic loading in these soils are high, the subgrade and underlying soft clay layers have become increasingly overloaded due to a lack of maintenance, and notable subgrade settlements have often been observed, which may exceed the acceptable limits and even compromise the functionality of the infrastructure [1]. Understanding the deformation behavior of soft clay deposits under traffic loads is important to predict lifetime serviceability of existing transport infrastructures and ensure the safe design of the engineering.
The permanent deformation measurement of soils under traffic loading is generally performed using undrained oneway cyclic triaxial tests with constant confining pressure (CCP). In these one-way cyclic triaxial tests, traffic loading was simulated by a single cyclic deviatoric stress only, which is purely compressive without reversal. A number of empirical models have been proposed to predict the permanent strain of soft soil due to repeated traffic loading [2-5]. Meanwhile, with combined shakedown theory, scholars also found that there is a cyclic stress threshold beyond which significant plastic strain occurs in a soil; otherwise, the changes in cyclic strain are extremely small or negligible, which can be used as a design criterion for pavement subgrade $[6,7]$. The cyclic strain accumulation model establishment and cyclic stress threshold determination in soft clay have become the theoretical basis for solving the problems of subgrade settlement under long-term cyclic loads induced by various transportation facilities. However, in spite of a great amount of research, the complex behavior 
of soft clay under cyclic traffic loading is not totally understood yet, while a satisfactory progress has been made in the simulation of the in situ stress paths and drainage conditions in the subsoil induced by cyclic traffic loading with the upgrade of experimental equipment. Actually, the dynamic stress field in the subsoil caused by cyclic traffic load is extremely complex. The soil in pavement experiences both transient axial and lateral stress as a wheel moves over [8], which can be simulated by the cyclic triaxial test with variable confining pressure (VCP) [9-11]. In addition, excessive pore-water pressure in soft clay arises and dissipates simultaneously or alternatingly during traffic loading, indicating that the condition of clayey subsoils subjected to traffic loading could be considered as partially drained, which can be simulated by open drainage lines during the applications of cyclic loads [12]. These findings suggest that both the purely deviatoric cyclic loading and the undrained conditions are not appropriate to reflect the real conditions in the subgrade due to cyclic traffic loading.

The effect of drainage and variable confining pressure on permanent deformation behavior and cyclic stress threshold of soft clay has not been sufficiently studied. Cai et al. [10] studied the VCP effects on the permanent deformation of remolded saturated soft clay with an identical initial stress in both undrained and partially drained conditions and suggested that the VCP tests are more appropriate for the simulation of the in situ loading conditions of traffic loading than CCP tests. The results also showed that neglecting the effect of VCP in partially drained condition will lead to a relatively smaller permanent strain result, which is not safe in engineering application. Sun et al. [11] presented an empirical model to predict the permanent axial strain of intact soft clay in partially drained conditions, considering the VCP effects. Gu et al. [13] further investigated the VCP effects on the permanent deformation behaviors of overconsolidated saturated clay in partially drained conditions. Test results in their studies, where VCP has been considered, all show a higher rate of plastic strain accumulation than that exhibited when only the vertical stress is cycled in partially drained conditions. Cyclic changes in the magnitude of horizontal stresses are, therefore, likely to significantly influence the observed plastic behavior of soils. However, these studies were focused on evaluating the influence of VCP on the permanent axial strain at a given number of cycles (e.g., $N=10000$ ), and only three stress paths have been considered, which resulted in incomplete understanding of the whole evolution of strain accumulation in subsoil under the coupling effect of vertical and lateral cyclic stresses induced by traffic loading. Also, the cyclic stress threshold for the control criteria of subgrade settlement was not proposed in previous studies.

Therefore, this paper intends to analyze the deformation behavior of Wenzhou soft marine clay in partially drained condition as indicated by CCP and VCP tests. The study focuses on the analysis of the effect of the stress level and stress paths on the permanent axial strain, and a new prediction model was established. Additionally, a cyclic deviator stress ratio threshold determined by the CCP tests in partially drained condition is suggested as an upper boundary in pavement subgrade design on Wenzhou soft marine clay. The findings from the current research advanced the understanding of deformation characteristics of soft marine clay under traffic load.

\section{Laboratory Experimental Program}

The soft clay samples used in this study were obtained from a deep excavation site in Wenzhou at a depth of 10-12 m, where problematic soils with high water content, high compressibility, low permeability, and low bearing capacity are often encountered [14]. The main physical properties of the tested soils are listed in Table 1. Figure 1 presents the conventional oedometer test results on the undisturbed sample. It can be observed that the preconsolidation pressure $\sigma_{p}$ was $98 \mathrm{kPa}$.

Testing was performed using a dynamic triaxial apparatus (DTA), manufactured by GDS Instruments Ltd. The DTA, which tests specimens with $50 \mathrm{~mm}$ diameter and $100 \mathrm{~mm}$ height, is described in many literatures [10, 11], which give details of the actuators, signal conditioning, and cyclic control systems. In this apparatus, the vertical stress is applied by a servo-loading system, while the confining pressure is supplied through an oil pressure type of piston. Images of the cyclic triaxial device and schematic diagram of the apparatus are shown in Figure 2.

Prior to each cyclic experiment, cylindrical specimens of $50 \mathrm{~mm}$ diameter and $100 \mathrm{~mm}$ height were firstly handtrimmed from the core of every sample by a wire saw in a rotary manner in a sample preparation platform and then mounted in the triaxial cell. Following this, a backpressure of $300 \mathrm{kPa}$ with an effective stress of $10 \mathrm{kPa}$ was applied until B values of the B-check process are greater than 0.98. Subsequently, all specimens were isotropically consolidated under a mean effective confining pressure of $100 \mathrm{kPa}$, which is slightly larger than the preconsolidation pressure $\sigma_{p}$ to make sure that the tested soft clay is normally consolidated. Then, the designed stress paths were conducted through independently controlled half-sine form deviator and isotropic stress to simulate the coupling of cyclic vertical normal stresses and cyclic horizontal normal stresses induced by moving wheel load. As suggested by Cai et al. [10], six filter strips of the same size are attached around the specimens and connected with both the upper and bottom porous stones as drainage paths. The pore water in the specimen is discharged into the backpressure system under the action of cyclic load and can be used to calculate the volumetric strain.

Figure 3 illustrates the stress paths in the stress plane of $p$-q. In Figure 3, the parameter $\eta^{a m p l}$ was introduced following RondóN et al. [9] to facilitate the investigation into the coupling effects of cyclic deviator and confining stresses, which are defined as $q^{a m p l} / p^{a m p l}$, in which $q^{a m p l}$ is the amplitude of cyclic deviator stress and $p^{a m p l}$ is the amplitude of cyclic mean principal stress. $p^{\text {ampl }}$ is calculated by $p^{a m p l}=$ $\left(\sigma_{1}^{a m p l}+2 \sigma_{3}^{a m p t}\right) / 3$, in which $\sigma_{3}{ }^{a m p l}$ is the amplitude of cyclic compressive confining pressure. In accordance with the 
TABle 1: Physical properties of Wenzhou soft clay.

\begin{tabular}{lc}
\hline Index properties & Values \\
\hline Specific gravity, $G_{\mathrm{s}}\left(\mathrm{g} / \mathrm{cm}^{3}\right)$ & 2.71 \\
Natural water content, $w_{n}(\%)$ & 59.7 \\
Initial density, $\rho_{0}\left(\mathrm{~g} / \mathrm{cm}^{3}\right)$ & 1.65 \\
Initial void ratio, $e_{0}$ & 1.62 \\
Liquid limit, $w_{L}(\%)$ & 60 \\
Plasticity index, $I_{\mathrm{p}}$ & 37 \\
Clay fraction $(\%)$ & 41 \\
Silt fraction $(\%)$ & 55 \\
\hline
\end{tabular}

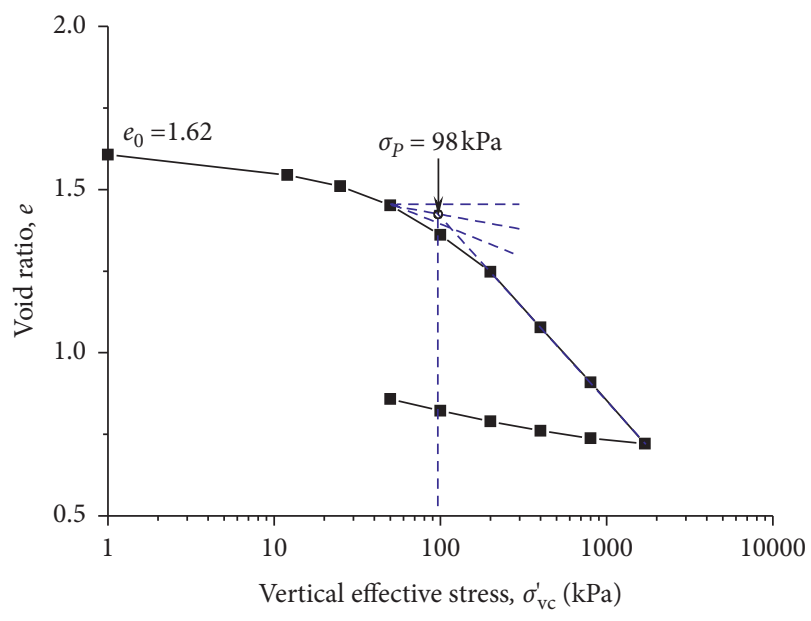

Figure 1: Compression curve of samples from odometer test.

nature of the CCP tests, the slopes of the stress paths in $p-q$ space are always constant and equal to 3. For the VCP tests, the slopes of the stress paths are dependent on the actual stresses applied.

The detailed test program is illustrated in Table 2, including 21 tests with different combinations of CSR and $\eta^{a m p l}$ values. The cyclic stress ratio (CSR) is defined as $\mathrm{CSR}=q^{a m p l} / q_{f}$, where $q_{f}$ is the static deviator stress at failure. The preliminary compression tests showed that $q_{f}$ is approximately $72 \mathrm{kPa}$ for the testing sample. All the tests were performed at room temperature (approximately $20^{\circ} \mathrm{C}$ ) according to the annual average temperature of Wenzhou. The loading frequency was set to $0.1 \mathrm{~Hz}$, and 50 test data points (one per $0.02 \mathrm{~s}$ ) were recorded per cycle according to the previous studies, and the number of cycles in the tests was set as 3,000. The reason for this particular choice in the number of cycles was driven by an analysis period compatible with laboratory work constraints and a practical method to characterize the mechanical behaviors of the soft clay.

\section{Test Results of Analysis}

3.1. Typical Axial Strain Accumulation in CCP and VCP Tests. Test results on the axial strain of the specimens in CCP and VCP tests are presented in this section. The permanent axial strain of subsoil can be used to evaluate the cumulative settlement of the subgrade under vehicle moving loads.
The typical deviatoric stress changes with the axial strain $\varepsilon_{a}$ of the specimens at CSR $=0.347$ and 0.625 obtained from CCP $\left(\eta^{a m p l}=3\right)$ and VCP $\left(\eta^{a m p l}=1,0.5\right)$ tests are selected and plotted in Figure 4 for the purpose of brevity. During the cyclic loading, all the stress-strain curves exhibit hysteresis and accumulation of irreversible axial plastic strains with the loading cycles, but the accumulation rate decreases with the cyclic numbers. These observations are in agreement with those observed in drained cyclic triaxial tests of granular materials (e.g., ballast and subballast) [15]. Figures 4(a)-4(d) indicate that the strain accumulation is dependent on both the $\eta^{a m p l}$ value and the level of the cyclic deviatoric stress. For example, for the specimen subjected to a $\mathrm{CSR}=0.278$, the permanent axial strain under the conditions of $\eta^{a m p l}=0.5(1.309 \%)$ is about 1.74 times greater than that of the specimen under the conditions of $\eta^{a m p l}=3(2.277 \%)$, which suggests that higher cyclic confining pressure can effectively promote the development of permanent axial strain in a specimen.

To achieve a better view of the influence of deviatoric stress and variable confining pressure on the development of axial strain, the typical comparison of $\varepsilon_{a}$ among tests with the same CSR but different $\eta^{a m p l}$ values is plotted in Figure 5, while the comparison of $\varepsilon_{a}$ among tests with the same $\eta^{a m p l}$ but different CSR values is presented in Figure 6. In general, all the shapes of the time-history curves of $\varepsilon_{a}$ are similar to each other except for the magnitudes, and $\varepsilon_{a}$ tends to reach a steady value at the end of the tests regardless of $\eta^{\text {ampl }}$ and CSR. Otherwise, under identical conditions, the increase of both deviatoric and isotropic stress amplitudes will promote the accumulation of $\varepsilon_{a}$ greatly. As shown in Figure 5(b), $\varepsilon_{a}$ can be divided into permanent axial strain $\varepsilon^{p}{ }_{a}$ and resilient strain $\varepsilon_{a}^{r}$. While, in Figure 5, the difference in the variation of $\varepsilon^{r}{ }_{a}$ with cycle numbers is relatively small, and it cannot be said how cyclic confining pressure affects it, the difference in the $\varepsilon^{p}{ }_{a}$ with cycle numbers is significant. Higher $\eta^{a m p l}$ values resulted in a larger $\varepsilon^{p}{ }_{a}$ with the same CSR values and cycle numbers. Figure 6 reveals that, for given $\eta^{a m p l}$ and $N$, both the $\varepsilon_{a}^{r}$ and $\varepsilon^{p}{ }_{a}$ are consistently larger if the CSR is higher. Furthermore, Figure 5 shows that the trend of $\varepsilon_{a}^{r}$ and $\varepsilon^{p}{ }_{a}$ with $\eta^{a m p l}$ is not extremely different at two different CSR values, which means that the stress paths effect does not depend significantly on CSR.

3.2. Permanent Axial Strain in CCP and VCP Tests. The development of permanent axial strain, $\varepsilon_{a}{ }^{p}$, with the number of load applications in CCP and VCP tests, is shown in Figure 7, similar to the variation of permanent axial strain of granular materials due to one-way cyclic loading in free to drained conditions [15]. It is clear from Figure 7 that the growth of permanent axial strain of these specimens with increasing number of cycles can be divided into initial consolidation phase (1-10 cycles), development phase (10-1,000 cycles), and stable phase (after 1,000 cycles). In the initial 10 cycles, the increase of $\varepsilon_{a}^{p}$ with cyclic numbers occurs slowly. In the later phases, the $\varepsilon_{a}^{p}$ grew rapidly with cyclic numbers and reached stability after 1,000 cycles. This phenomenon may be attributed to the partially drained 


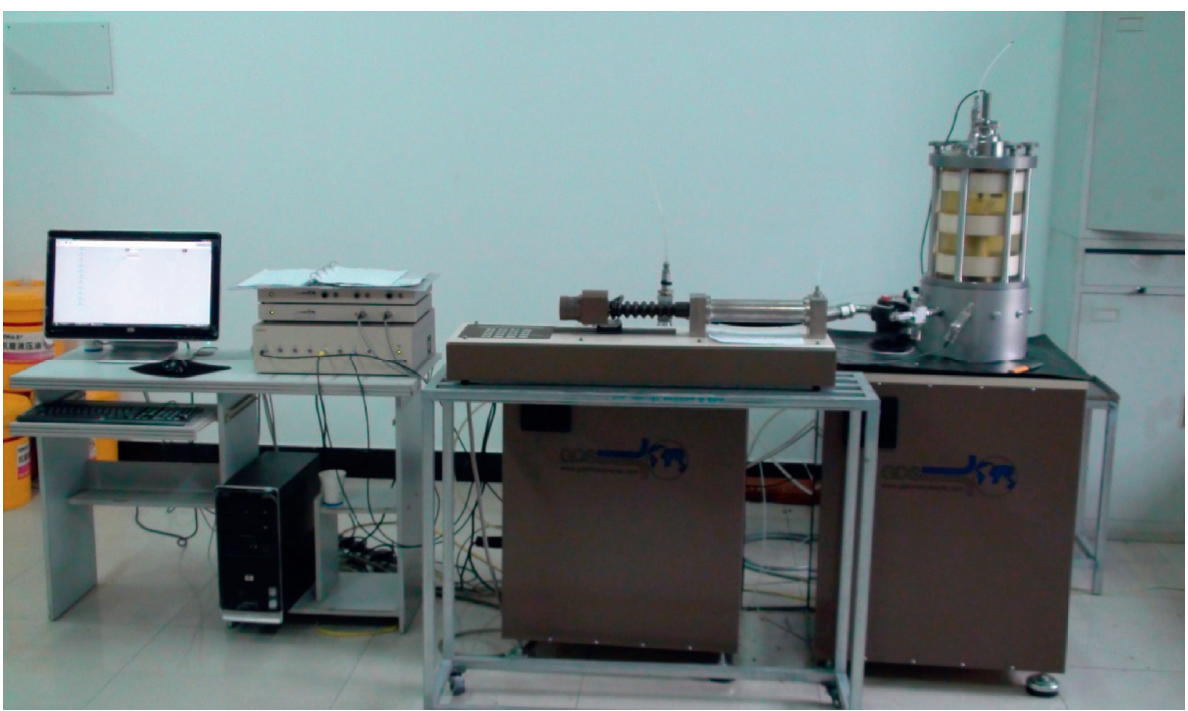

(a)

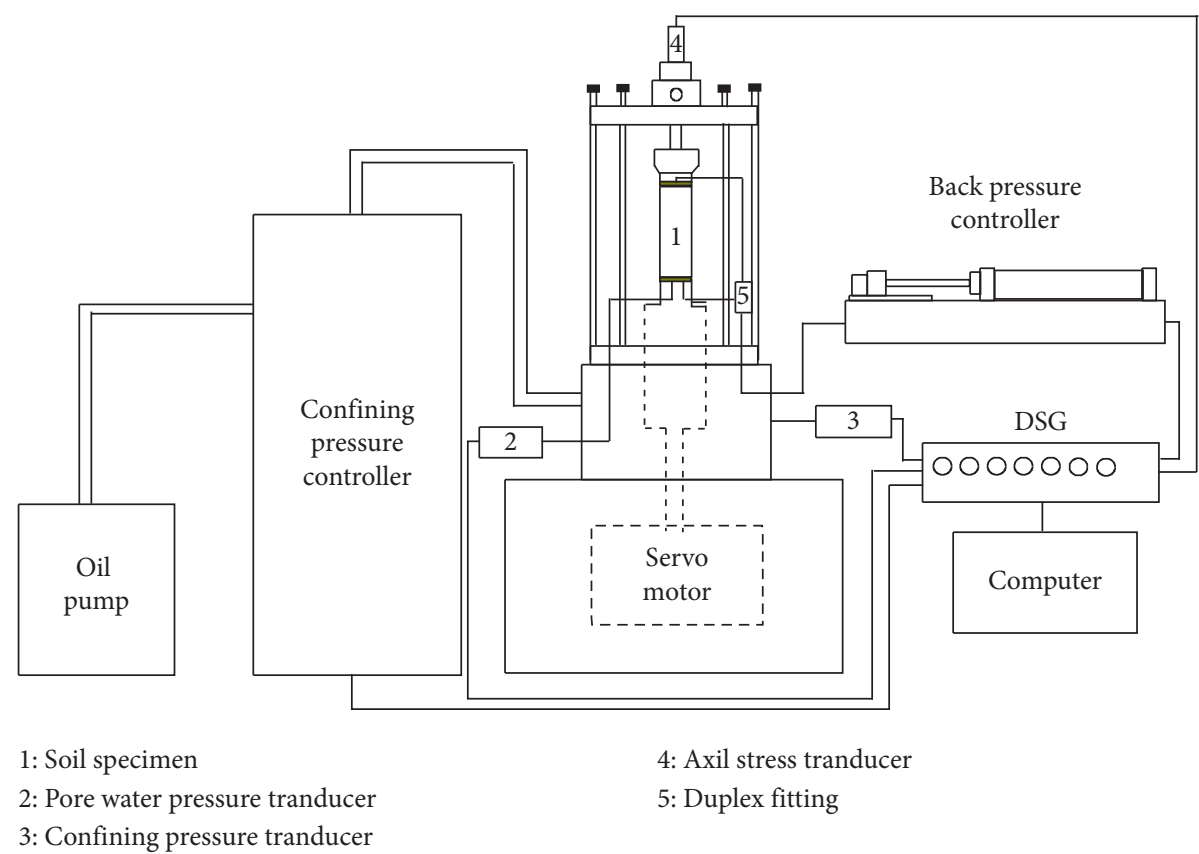

(b)

Figure 2: (a) General view of the apparatus. (b) Schematic diagram of advanced cyclic triaxial device.

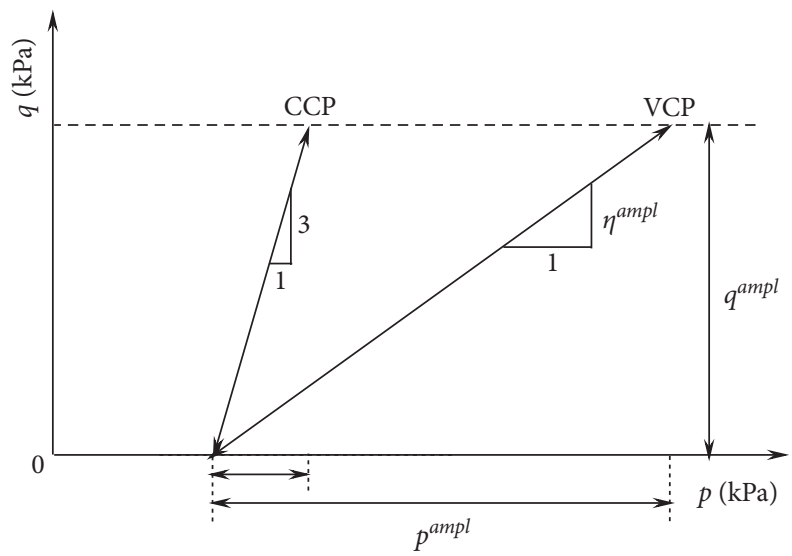

FIGURE 3: Stress paths of the tests in $\mathrm{p}-\mathrm{q}$ space. 
TABLE 2: Scheme of CCP and VCP tests.

\begin{tabular}{|c|c|c|c|c|c|}
\hline Number of tests & $p_{0}^{\prime}(\mathrm{kPa})$ & $q^{a m p l}(\mathrm{kPa})$ & CSR & $\eta^{a m p l}$ & Number of load cycles \\
\hline D01 & 100 & 15 & 0.208 & 3 & 3000 \\
\hline D02 & 100 & 15 & 0.208 & 1.0 & 3000 \\
\hline D03 & 100 & 15 & 0.208 & 0.5 & 3000 \\
\hline D04 & 100 & 20 & 0.278 & 3 & 3000 \\
\hline D05 & 100 & 20 & 0.278 & 1.0 & 3000 \\
\hline D06 & 100 & 20 & 0.278 & 0.5 & 3000 \\
\hline D07 & 100 & 20 & 0.278 & 0.4 & 3000 \\
\hline D08 & 100 & 20 & 0.278 & 0.3 & 3000 \\
\hline D09 & 100 & 25 & 0.347 & 3 & 3000 \\
\hline D10 & 100 & 25 & 0.347 & 1.0 & 3000 \\
\hline D11 & 100 & 25 & 0.347 & 0.5 & 3000 \\
\hline D12 & 100 & 35 & 0.486 & 3 & 3000 \\
\hline D13 & 100 & 35 & 0.486 & 1.0 & 3000 \\
\hline D14 & 100 & 35 & 0.486 & 0.5 & 3000 \\
\hline D15 & 100 & 35 & 0.486 & 0.4 & 3000 \\
\hline D16 & 100 & 45 & 0.625 & 3 & 3000 \\
\hline D17 & 100 & 45 & 0.625 & 1.0 & 3000 \\
\hline D18 & 100 & 45 & 0.625 & 0.5 & 3000 \\
\hline D19 & 100 & 55 & 0.764 & 3 & 3000 \\
\hline D20 & 100 & 60 & 0.833 & 3 & 3000 \\
\hline D21 & 100 & 65 & 0.903 & 3 & 3000 \\
\hline
\end{tabular}

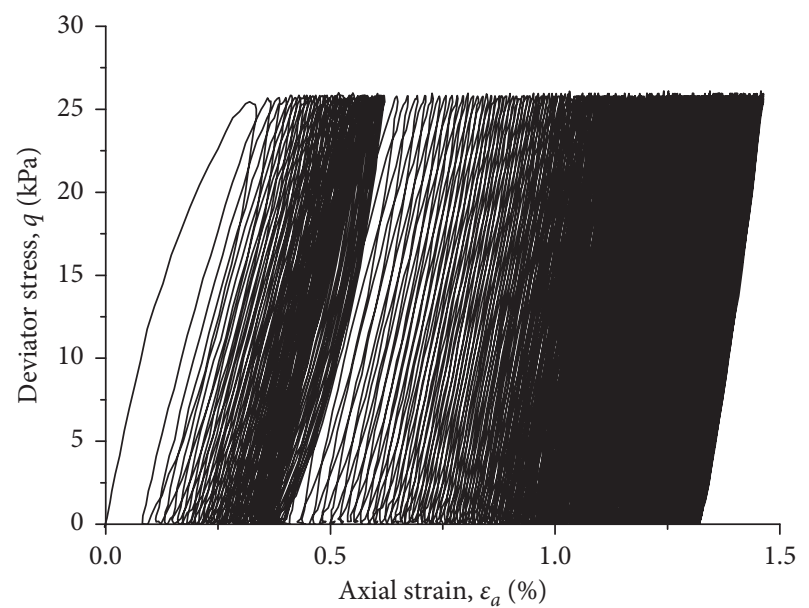

(a)

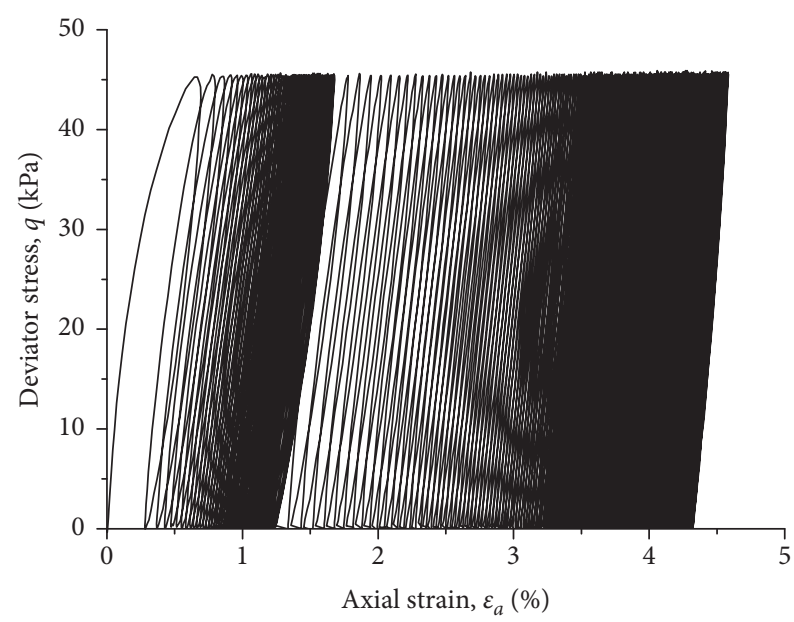

(c)

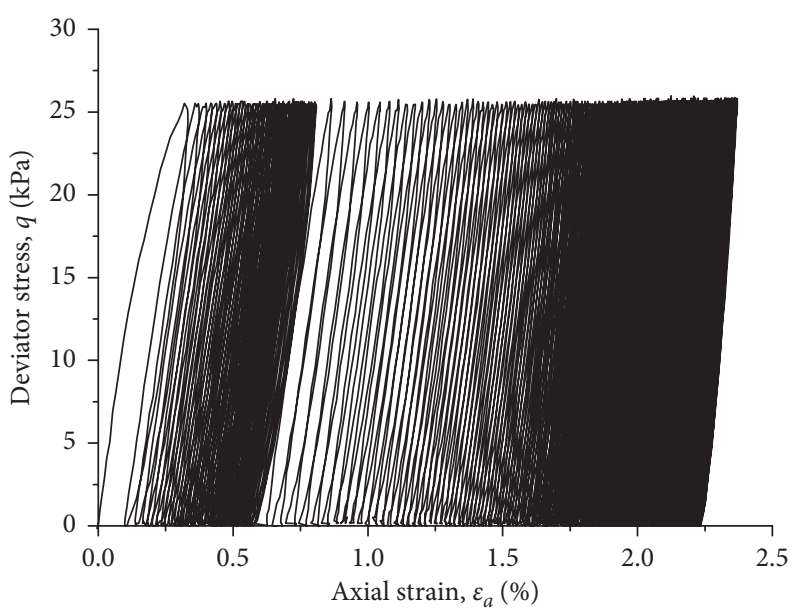

(b)

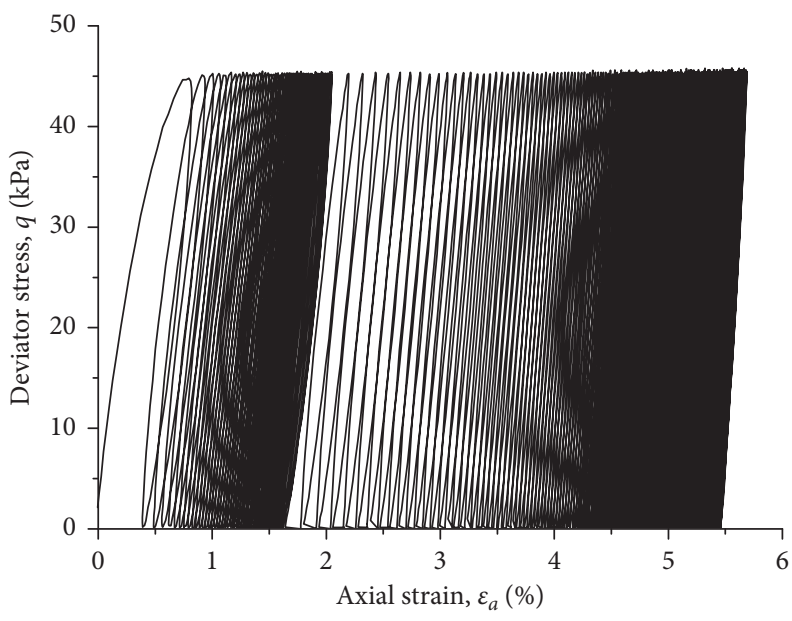

(d)

FIGURE 4: Typical stress-strain hysteretic loops: (a) $\operatorname{CSR}=0.347, \eta^{a m p l}=3$; (b) $\operatorname{CSR}=0.347, \eta^{\text {ampl }}=0.5$; (c) $\operatorname{CSR}=0.625, \eta^{\text {ampl }}=1$; (d) $\operatorname{CSR}=0.625, \eta^{\text {ampl }}=0.5$. 


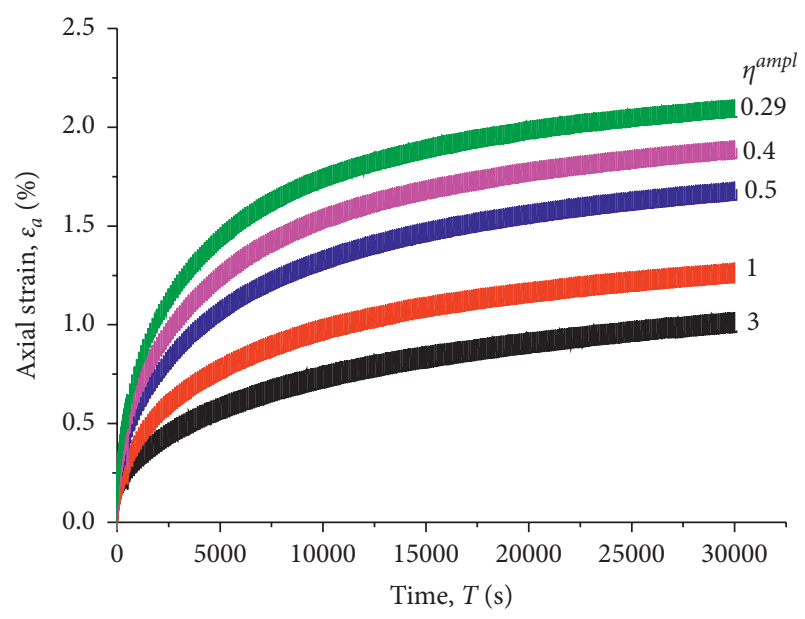

(a)

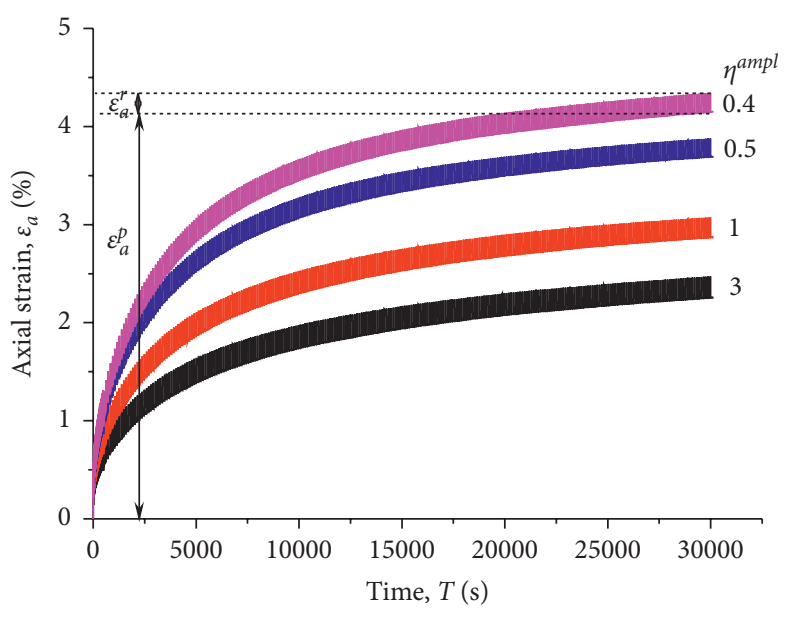

(b)

FIgURE 5: Typical time-history curves of axial strains: (a) $\operatorname{CSR}=0.278$; (b) $\operatorname{CSR}=0.486$.

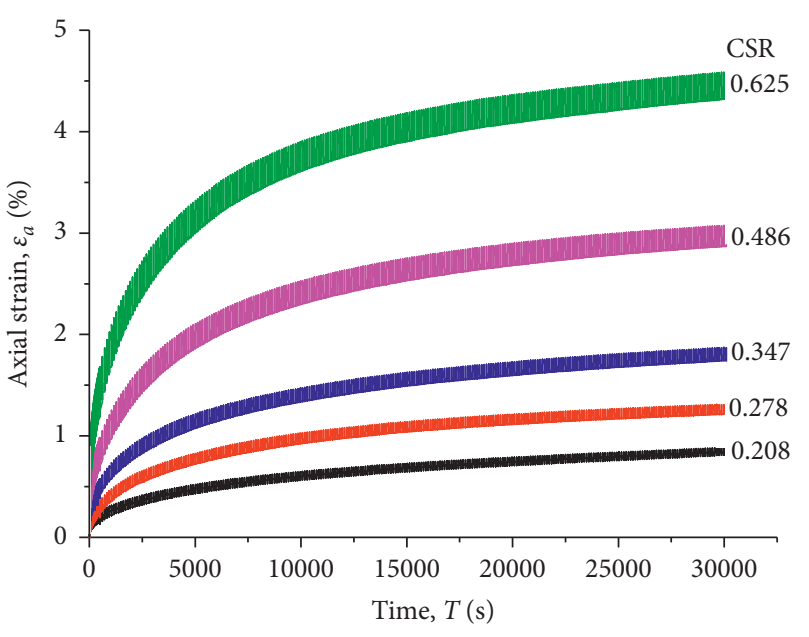

(a)

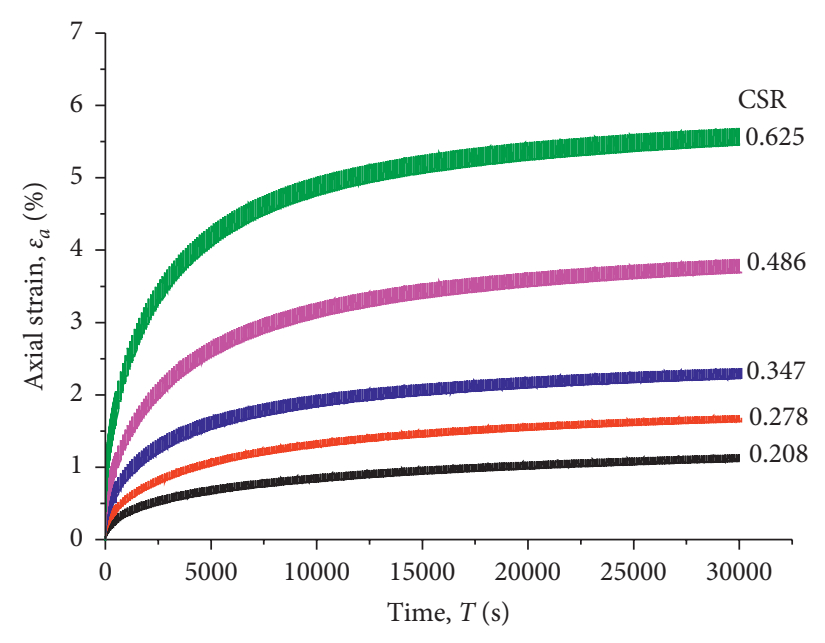

(b)

Figure 6: Typical time-history curves of axial strains: (a) $\eta^{a m p l}=1$; (b) $\eta^{a m p l}=0.5$.

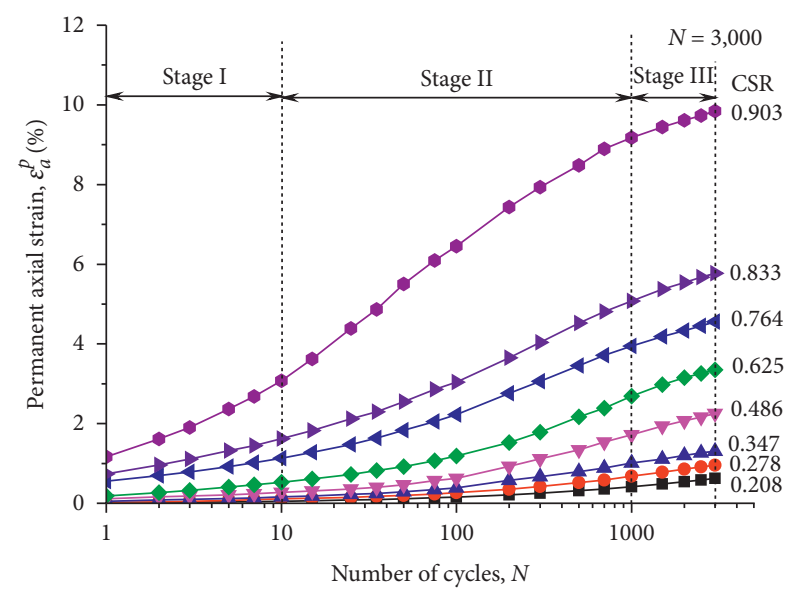

(a)

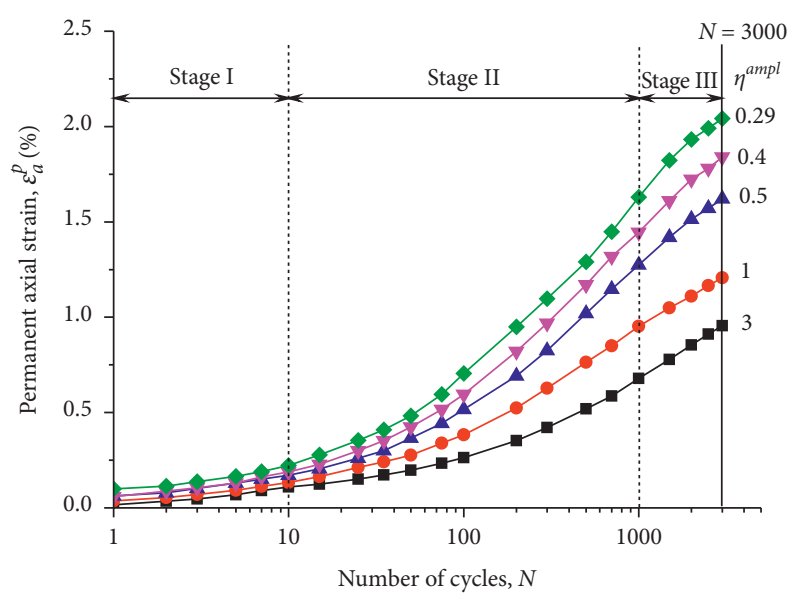

(b)

FIGURE 7: Relationships between permanent axial strains and cycle numbers: (a) $\eta^{a m p l}=3$; (b) CSR $=0.278$. 
effect. During cyclic loading, the specimens were compacted continuously through water removal, and the compaction effect began to decrease until a particular number of cycles (i.e., $N \geq 1,000$ ).

A better view of the permanent axial strain $\varepsilon_{a}^{p}$ influenced by the magnitude of deviatoric stress, for tests with $\eta^{a m p l}=1$ and $0.5, \varepsilon_{a}^{p}$ at selected cycle numbers (e.g., $N=10,50,100$, $500,1,000$, and 3,000) versus CSRs, is presented in Figure 8. It can be found that $\varepsilon_{a}^{p}$ is linearly varied with CSR in a log$\log$ plot. For a given number of cycles, the relationship between $\varepsilon_{a}^{p}$ and CSRs can be written as follows:

$$
\varepsilon_{a}^{p}=A C S R^{B},
$$

in which $A$ and $B$ are fitting parameters depending on the applied cycle numbers and $\eta^{\text {ampl }}$ values.

According to the previous CCP and VCP tests on granular materials [9], A consistent pattern was observed between $\varepsilon_{a}{ }^{p}$ and stress path length, $L$, which can be used to characterize the influence of cyclic confining pressure on the development of permanent axial strain $\varepsilon_{a}^{p}$. Therefore, the effect of $L$ on $\varepsilon_{a}^{p}$ of soft clay in this study is presented in Figures 9(a) and 9(b). It can be seen that the trends of $\varepsilon_{a}{ }^{p}$ with $L$ at different cycle numbers or CSR values are similar. For a given value of CSR and $N$, the amount of $\varepsilon_{a}{ }^{p}$ increases with $L$, which can be expressed by a logarithmic expression of $y=a \ln (x)+b$. Figure 9 also indicates that the effect of $L$ on the magnitude of $\varepsilon_{a}{ }^{p}$ depends on both the CSR values and $N$. $\varepsilon_{a}{ }^{p}$ is found to increase with the increase of both $N$ and CSR at the same $L$ values. This observation further indicates the significant influence of deviatoric stress magnitude and cycle numbers on the strain accumulation in soft clay.

Figure 10 further presents the normalized result of Figure 9(b), indicating that the normalized permanent axial strain after 1000 cycles $\left(\varepsilon_{a, 1000}^{p} / \varepsilon_{a, 1000}^{p, C C P}\right)$ is logarithmically related to the normalized stress path length $\left(L / L_{C C P}\right)$, regardless of the CSR values.

Figure 11 plots the permanent axial strain at $N=1000$, $\varepsilon_{a, 1000}^{p}$ versus the amplitude of cyclic confining pressure $\sigma_{3}^{\text {ampl }}, w_{n}$ in each test according to the data processing method of Cai et al. [10]. As can be seen, for tests with the same CSR value, $\varepsilon_{a, 1000}^{p}$ at $N=1000$ is basically proportional to $\sigma_{3}^{\mathrm{ampl}}$, and the $\sigma_{3}^{\mathrm{ampl}}$ lines for different CSR values are almost parallel to each other (i.e., identical inclinations).

Figure 12 further plots the increment of the permanent axial strain $\Delta \varepsilon_{a, 1000}^{p}$ versus the corresponding increment of the amplitude of cyclic confining pressure $\Delta \sigma_{3}^{\text {ampl }}$. It can be seen that $\Delta \varepsilon_{a, 1000}^{p}$ is generally proportional to $\Delta \sigma_{3}^{\text {ampl }}$ regardless of the CSR values, indicating that one-unit increment in the amplitude of cyclic confining pressure will induce an increment of $0.0213 \%$ in the permanent axial strain at $N=1000$, independent of the CSR values. The relationship established between $\Delta \varepsilon_{a}^{p}$ and $\Delta \sigma_{3}^{\text {ampl }}$ allows the prediction of permanent axial strain at a given cycle number and stress path.

To achieve a better view of the importance of cyclic confining pressure, the influence of $\eta^{a m p l}$ values on the permanent axial strain $\varepsilon_{a}{ }^{p}$ is quantified. As can be seen from the comparisons of $\varepsilon_{a}{ }^{p}$ between VCP and corresponding
CCP tests in Figure 13, (a) linear relationship was observed when the VCP permanent axial strain, $\varepsilon^{p}{ }_{a, V C P}\left(\eta^{a m p l}=1,0.5\right.$, 0.4 and 0.29$)$, was plotted against the counterparts $\varepsilon^{p}{ }_{a, C C P}$ in CCP tests $\left(\eta^{a m p l}=3\right)$. Furthermore, the fitting parameters $k$ represent the ratios of $\varepsilon_{a}^{p}$ to $\varepsilon^{p}{ }_{a, C C P}$ plotted versus the $\eta^{a m p l}$ values and are shown in Figure 14. To investigate the effects of the $\eta^{a m p l}$ values, the $k$ - $\eta^{\text {ampl }}$ relationship can be closely approximated using the following form:

$$
k=a\left(\eta^{a m p l} / 3\right)^{b}+c
$$

in which $a, b$, and $c$ are fitting parameters. According to equation (2), the regression analyses of these data resulted in the following equation, which can be used to predict the permanent axial strains of saturated soft clays under a certain combination cyclic deviator stress and cyclic confining pressure if the permanent axial strains in CCP tests are known.

$$
\varepsilon_{a}^{p}=\left(0.206\left(\eta^{a m p l} / 3\right)^{-0.855}+0.794\right) \varepsilon_{a, C C P}^{P}
$$

3.3. Cyclic Deviator Stress Ratio Threshold. Shakedown analyses provide a theoretical basis for pavement designs and safety assessments [16]. According to the shakedown concept, the soft clay due to repeated loading can be divided into stable (i.e., shakedown or resilient behavior) and unstable response (i.e., excessive permanent deformation occurs). Based on the cyclic response (i.e., permanent deformation, resilient modulus), a cyclic stress threshold can be determined to compute the load-carrying capacity of the soft clay subgrades or limit the subgrade stress for prevention of excessive plastic strain. Therefore, a better insight into the deformation behavior of soft clay under repeated loading is imperative to reach a more definite and reliable classification of shakedown response.

Through the above mentioned analysis, it can be found that VCP tests resulted in a larger permanent axial strain than the corresponding CCP tests. The threshold of cyclic deviatoric stress ratio determined by the CCP test results can be used as an upper bound of criterion to discerning whether the growth of plastic strains will eventually level off or exhibit an incremental failure. Because the permanent axial strain has reached a stable state after 1,000 cycles, herein, the permanent axial strain of specimens at 1,000 cycles, $\varepsilon^{p}$ a,1000, was plotted against the CSR values in Figure 15. An approach similar to that used by Mitchell et al. [17] (i.e., by locating the points at which the experimental stress-strain curves showed a marked bend) was used to determine the threshold of cyclic deviatoric stress ratio from the diagram in Figure 15; it consists basically in locating the marked bend point at the intersection of the rectilinear extrapolations of the pre- and postincrease portions of the $\varepsilon^{p}{ }_{a, 1000^{-}}$CSR curve, while it should be noted that some subjectivity was unavoidable in locating the marked bend point as the curves were nonlinear from the beginning. In this study, the threshold of cyclic deviatoric stress ratio corresponding to the marked bend point of the $\varepsilon^{p}$ a,1000-CSR curve in Figure 15 


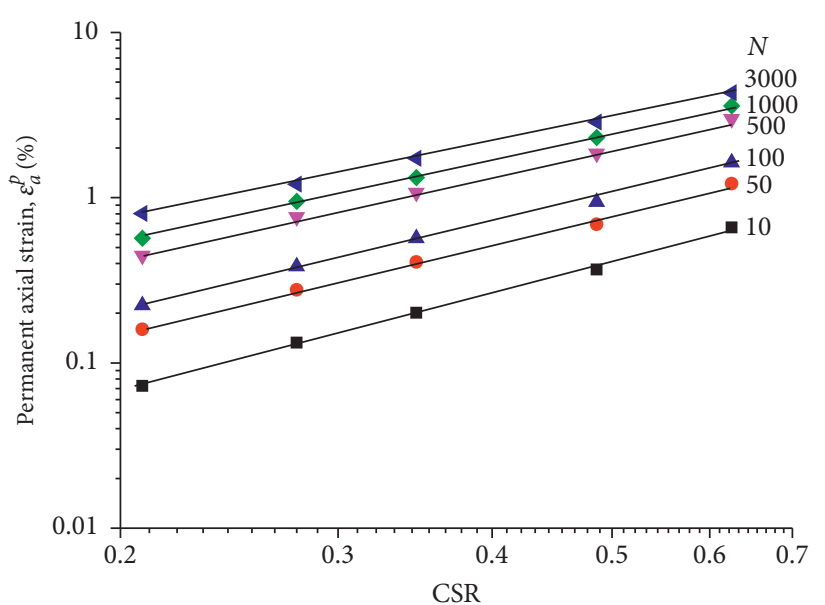

(a)

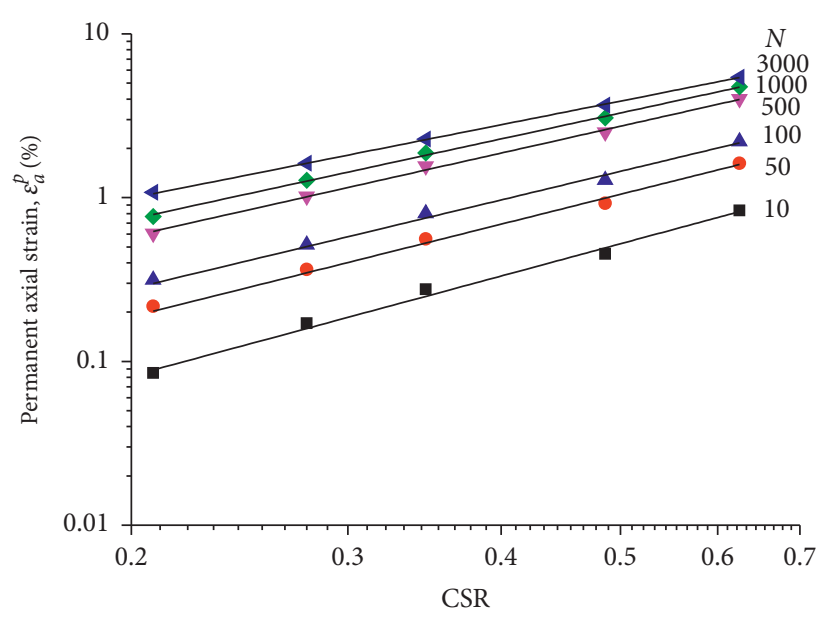

(b)

FIGURE 8: Relationships between permanent axial strains at selected cycle numbers and CSR: (a) $\eta^{a m p l}=1$; (b) $\eta^{a m p l}=0.5$.

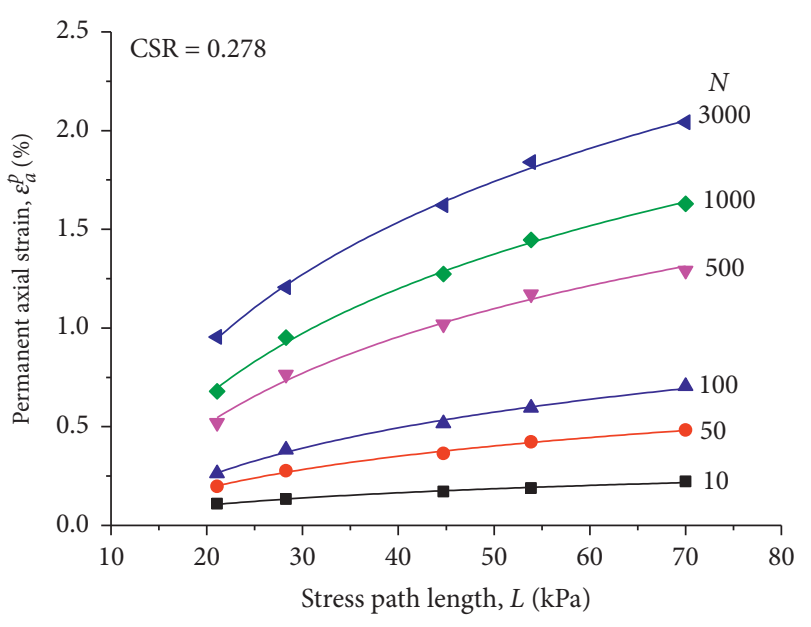

(a)

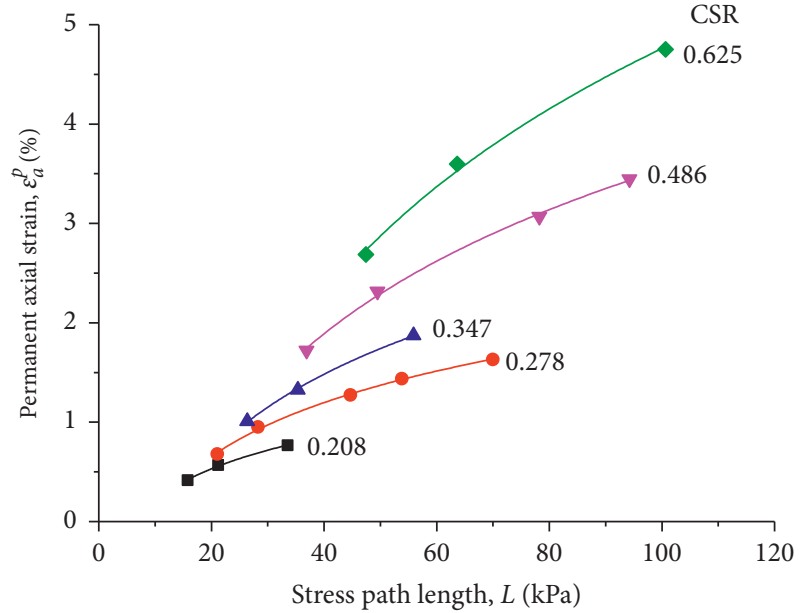

(b)

FIgURE 9: Permanent axial strain after 1000 cycles versus the length of stress path. (a) CSR $=0.278$.

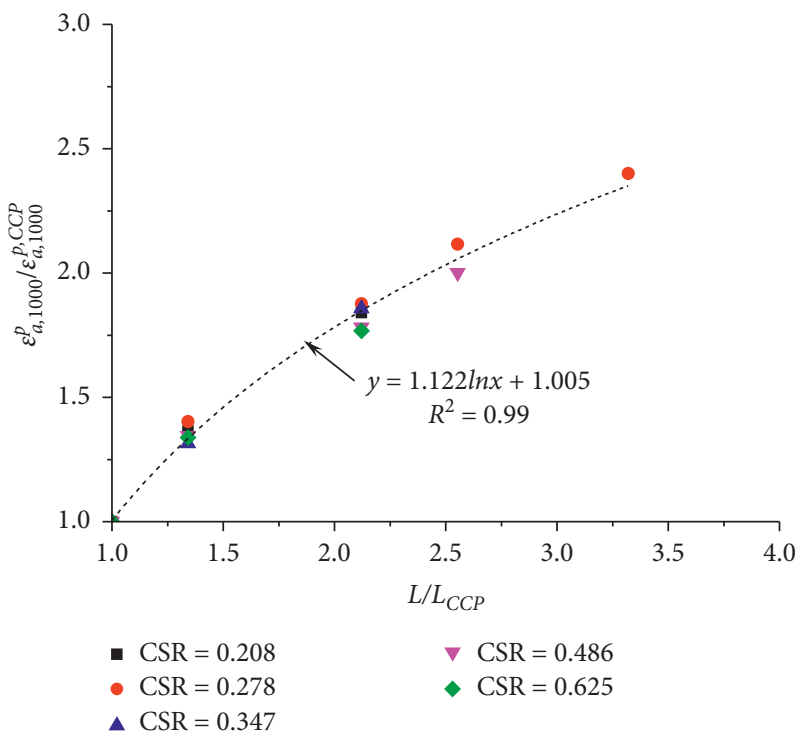

Figure 10: Normalized permanent axial strain after 1000 cycles versus the normalized length of stress path. 


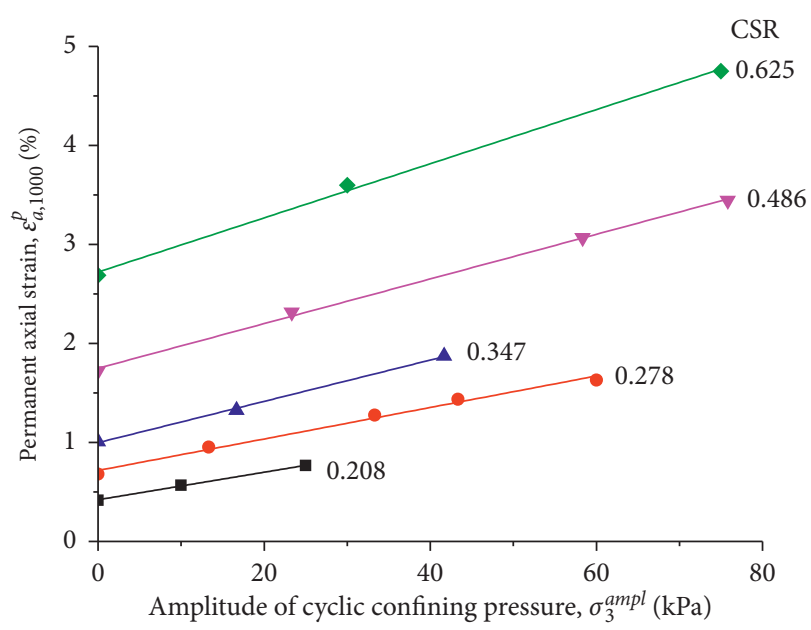

FIgURE 11: Relationships between the permanent axial strain at $N=1000$ versus the amplitude of cyclic confining pressure.

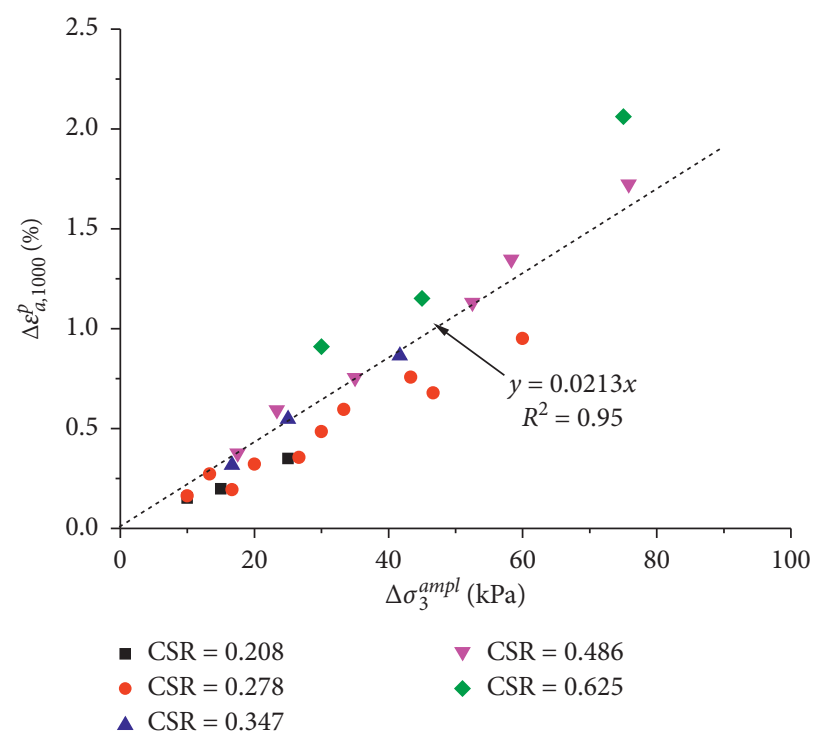

FIGURE 12: Relationships between the increment of permanent axial strain at $N=1000$ versus the increment of amplitude of cyclic confining pressure.

is about 0.7 , and that of the corresponding cyclic deviator stress threshold is $50.4 \mathrm{kPa}$. As expected, the permanent axial strain would exceed $5 \%$, while cycle time increases, which is occasionally adopted as a sign of failure [18]. Once the threshold of cyclic deviatoric stress ratio (0.7) was exceeded, small increases in cyclic deviator stress could trigger the rapid deterioration and failure of the previously stable soft subsoil, and such behavior corresponds to the incremental collapse stage of the shakedown concept. It is suggested that $\mathrm{CSR}=0.7$ could be suggested as a warning before subgrade invalidation in soft clay area of Wenzhou. This value has coincided with the allowable CSR obtained by cyclic triaxial tests on the same soil in undrained condition after isotropic consolidation [7].

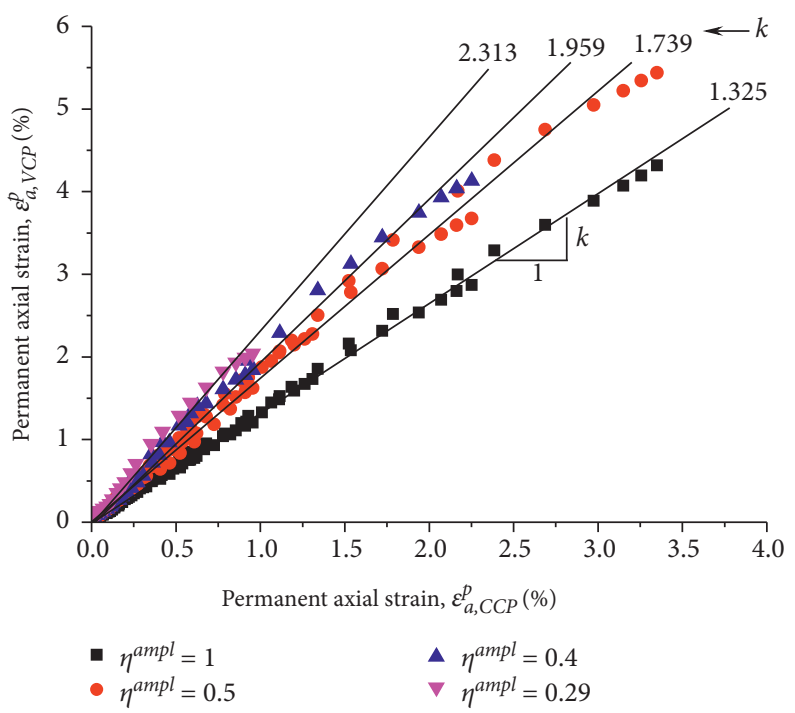

FIgURE 13: Relationships between permanent axial strains in VCP and CCP tests.

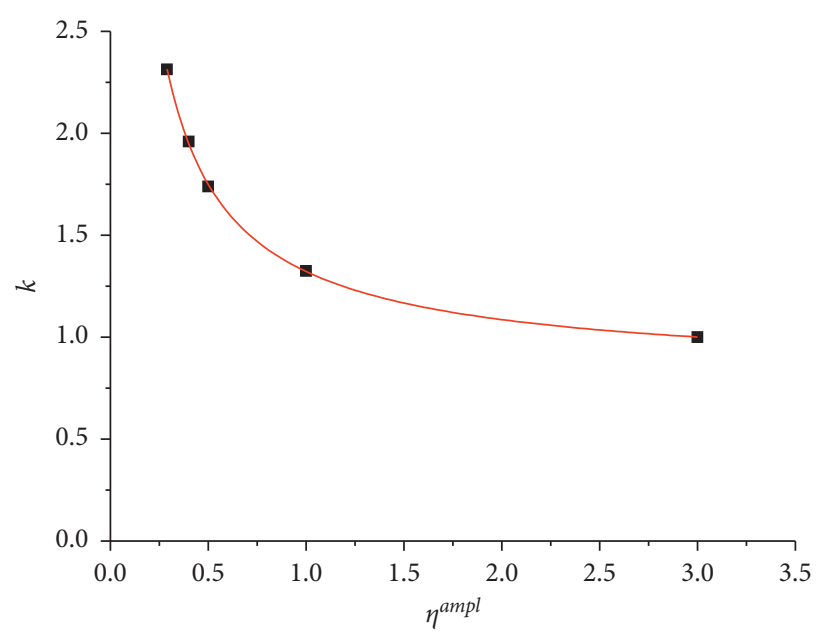

FIGURE 14: Relationships between $\mathrm{k}$ and $\eta^{\text {ampl }}$ values.

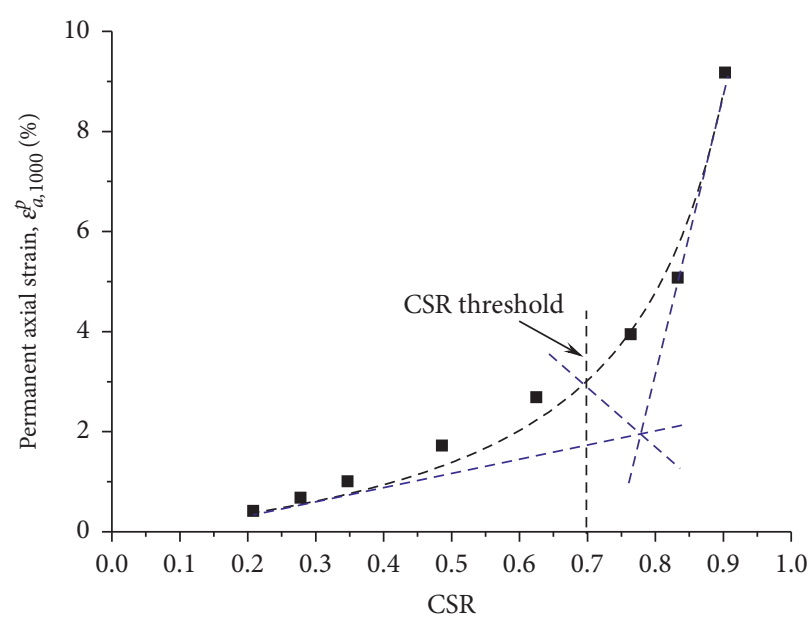

FIgURE 15: Relationships between $\varepsilon_{a, 1000}^{p}$, and CSR values. 


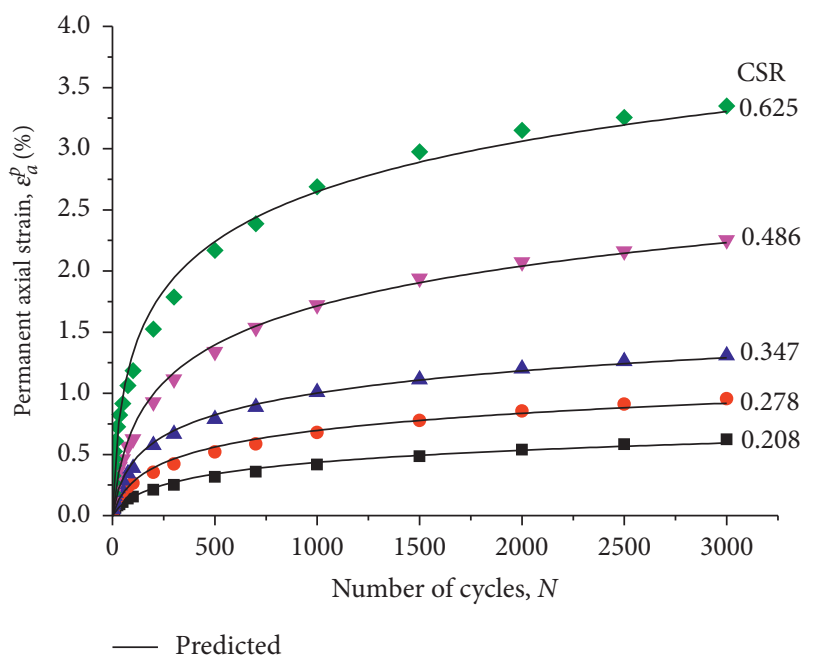

FIGURE 16: Development of permanent axial strain with increasing cycle numbers in CCP tests. $\eta^{\text {ampl }}=3$.

Table 3: Regression parameters $C_{1}$ and $C_{2}$ in equation (4).

\begin{tabular}{lccr}
\hline Test number & CSR & $C_{1}$ & $C_{2}$ \\
\hline D01 & 0.208 & 6.7094 & 0.0026 \\
D04 & 0.278 & 4.8348 & 0.0058 \\
D09 & 0.347 & 3.7465 & 0.0100 \\
D12 & 0.486 & 2.0861 & 0.0216 \\
D16 & 0.625 & 1.6655 & 0.0489 \\
\hline
\end{tabular}

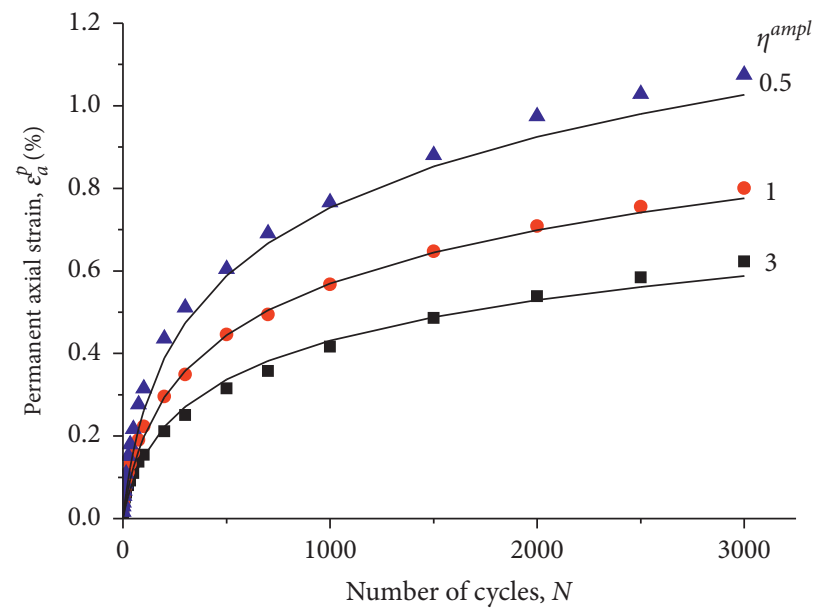

Calculated data

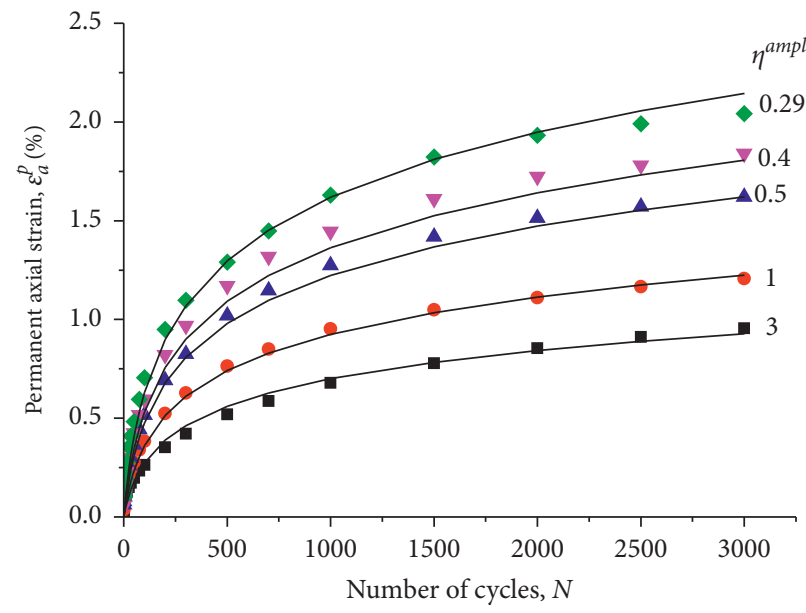

Calculated data

(a)

(b)

FIGURE 17: Continued. 


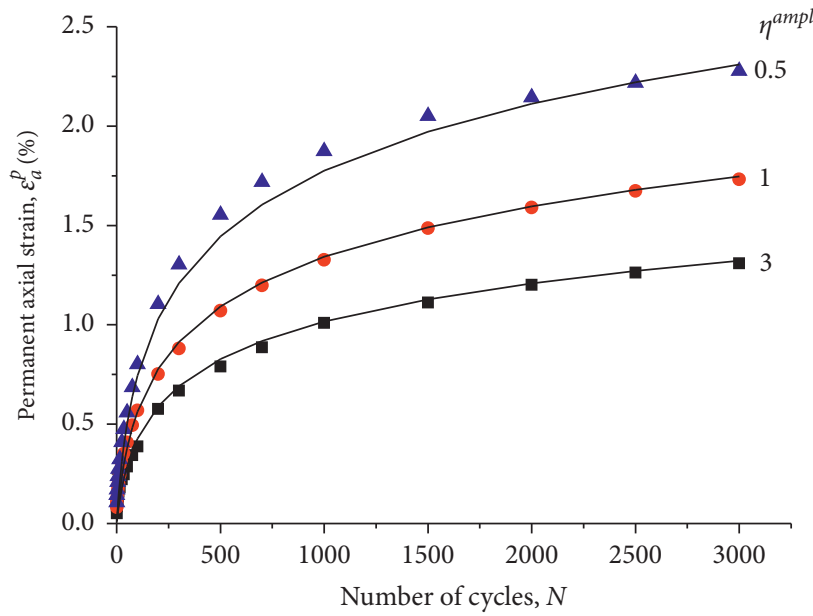

Calculated data

(c)

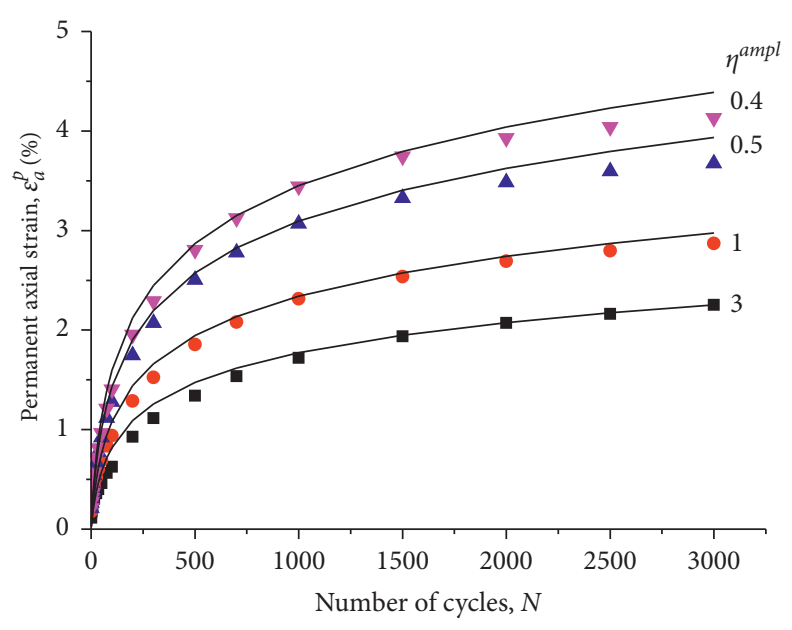

— Calculated data

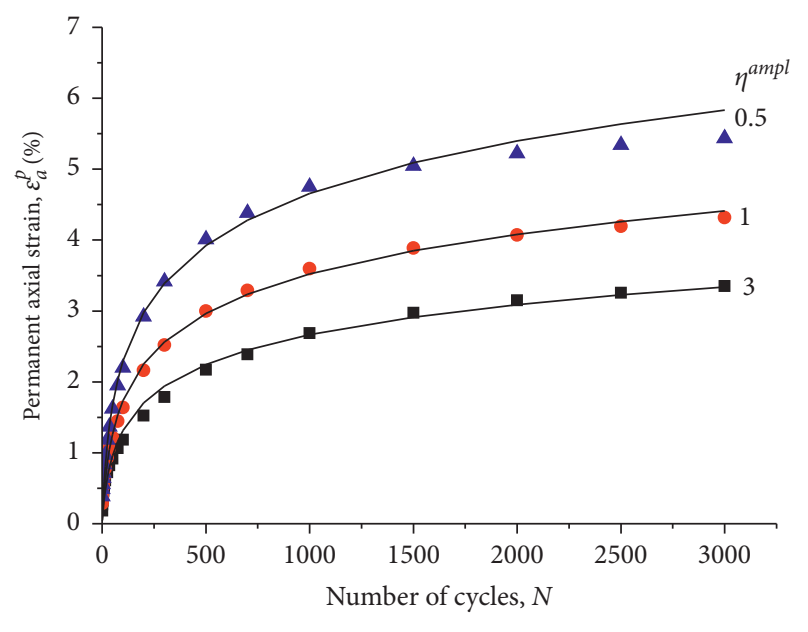

(d)

(e)

FIGURE 17: Comparison of the measured and calculated permanent axial strains. (a) CSR $=0.208$. (b) CSR $=0.278$. (c) CSR $=0.347$. (d) CSR $=0.486$. $(\mathrm{e}) \mathrm{CSR}=0.625$.

3.4. Permanent Axial Strain Empirical Model. Power modes and logarithmic models are the two most wide-spread approaches to describe the increase of permanent axial strain $\mathcal{E}^{p}{ }_{a}$ with increasing number of cycles $N$ [19]. Wichtmann et al. [19] have suggested that a logarithmic model is more appropriate for the residual strain description of soil in drained condition. Hence, a logarithmic model was used to fit the experimental data with CSR values below 0.7 in Figure 16, which is expressed as

$$
\varepsilon_{a, C C P}^{p}=\ln \left(1+C_{1} C_{2} N\right) / C_{1} .
$$

in which $C_{1}$ and $C_{2}$ are fitting parameters depending on the CSR values and are listed in Table 3 . The $C_{1}$-CSR and $C_{2}-$ CSR relationship can be expressed by a constitutive expression and a linear function of the following form, respectively:

$$
\begin{aligned}
& C_{1}=0.8712 C S R^{-1.321}, \\
& C_{2}=0.1555 C S R^{2.5998} .
\end{aligned}
$$

Setting equations (5) and (6) into equation (4), the final prediction equation for the permanent axial strain in CCP tests below CSR $=0.7$ is

$$
\varepsilon_{a, C C P}^{p}=\frac{\ln \left(1+0.8712 \operatorname{CSR}^{-1.321} \times 0.1555 \operatorname{CSR}^{2.5998} N\right)}{0.8712 C S R^{-1.321}} .
$$

Furthermore, setting Eq. (7) into equation (3), the permanent axial strain empirical model considering the effect of stress paths can be written as follows: 


$$
\begin{aligned}
\varepsilon_{a}^{p}= & \left(0.206\left(\eta^{a m p l} / 3\right)^{-0.855}+0.794\right) \\
& \times \frac{\ln \left(1+0.8712 C S R^{-1.321} \times 0.1555 \operatorname{CSR}^{2.5998} N\right)}{0.8712 C S R^{--.321}} .
\end{aligned}
$$

Figure 17 shows the comparison between measured permanent axial strain and the calculated data by Eq. (8), indicating that the empirical model formulation used here was able to well capture the permanent axial strain response of soft clay in partially drained conditions as a function of cyclic deviator stress, stress paths, and loading cycles. This model can be used to predict the permanent deformation that is expected in a coastal subgrade soil condition. However, it should be noted that the proposed formulation provided good predictions are due to the correlation coefficients used in the empirical model was derived from the same measured permanent axial strain response data against whom the comparisons were made. Owing to the limited amount of similar laboratory test data available, the applicability of this formula remains to be further verified, but the modeling method is worth considering.

\section{Conclusions}

A series of one-way CCP and VCP tests on an intact saturated soft marine clay were performed in this study. The combined effects of the vertical and horizontal stress changes to which subgrade soils are subjected are simulated by the combination of cyclic deviator stress and cyclic confining pressure. Based on the experimental results, the major conclusions are summarized as follows:

(1) The generation of axial strain is significantly affected by cyclic loading levels and stress paths. However, for all loading patterns considered, the normalized permanent axial strain at a given number of cycles can be uniquely related to the normalized stress path length, $L$, regardless of the CSR values.

(2) The increment of the permanent axial strain at a given number of cycles is generally proportional to the increment of the amplitude of cyclic confining pressure. One-unit increment in the amplitude of cyclic confining pressure will induce an increment of $0.0213 \%$ in the permanent axial strain at $N=1000$, independent of the CSR values.

(3) Based on CCP test results and shakedown theory, a CSR threshold of 0.7 was determined for Wenzhou soft marine clay, which can be suggested as a basis for controlling subgrade settlement in soft marine area.

(4) A logarithmic model of permanent axial strain provided an extremely good simulation of the measured permanent axial strain data of CCP and VCP test by not only accounting for the combined effects of cyclic deviatoric and confining stresses, but also accounting for the effects of cycle numbers.
(5) Future work in this area should address the effects of wave form, frequency, cyclic intermediate principal stress, rotation of principal stress, and a larger number of loading cycles on permanent strain potentials of soft marine clays.

\section{Data Availability}

The data used to support the findings of this study are available from the corresponding author upon request.

\section{Conflicts of Interest}

The authors declare no conflicts of interest.

\section{Acknowledgments}

This study was supported by the Nature Science Research Project of Anhui province (no. 1908085QE215) and professor/doctoral scientific research project of Suzhou College (no. 2016jb05).

\section{References}

[1] Y. Chen, "A combined method to predict the long-term settlements of roads on soft soil under cyclic traffic loadings," Acta Geotechnica: An International journal for Geoengineering, vol. 13, no. 5, pp. 1215-1226, 2018.

[2] C. L. Monismith, N. Ogaw, and C. R. Freeme, "Permanent deformation characteristics of subgrade soils due to repeated loading," Washington D.C., TRB, vol. 537, pp. 1-17, 1975.

[3] D. Li and E. T. Selig, "Cumulative plastic deformation for finegrained subgrade soils," Journal of Geotechnical Engineering, vol. 122, no. 12, pp. 1006-1013, 1996.

[4] J.-C. Chai and N. Miura, "Traffic-load-induced permanent deformation of road on soft subsoil," Journal of Geotechnical and Geoenvironmental Engineering, vol. 128, no. 11, pp. 907-916, 2002.

[5] X.-W. Ren, Q. Xu, J. Teng, N. Zhao, and L. Lv, "A novel model for the cumulative plastic strain of soft marine clay under long-term low cyclic loads," Ocean Engineering, vol. 149, pp. 194-204, 2018.

[6] M. W. Frost, P. R. Fleming, and C. D. F. Rogers, "Cyclic triaxial tests on clay subgrades for analytical pavement design," Journal of Transportation Engineering, ASCE, vol. 130, no. 3, pp. 78-86, 2004.

[7] L. Guo, J. Wang, Y. Cai, H. Liu, Y. Gao, and H. Sun, “Undrained deformation behavior of saturated soft clay under long-term cyclic loading," Soil Dynamics and Earthquake Engineering, vol. 50, pp. 28-37, 2013.

[8] F. Lekarp, U. Isacsson, and A. Dawson, "State of the art. II: permanent strain response of unbound aggregates," Journal of Transportation Engineering, vol. 126, no. 1, pp. 76-83, 2000.

[9] H. A. Rondón, T. Triantafyllidis, and A. Lizcano, "Comparison of cyclic triaxial behavior of unbound granular material under constant and variable confining pressure," Journal of Transportation Engineering, vol. 135, no. 7, pp. 467-478, 2009.

[10] Y. Wichtmann, C. Gu, J. Wang, C. H. Juang, C. Xu, and X. Hu, "One-way cyclic triaxial behavior of saturated clay: comparison between constant and variable confining pressure," Journal of Geotechnical and Geoenvironmental Engineering, vol. 139, no. 5, pp. 797-809, 2013. 
[11] L. Sun, C. Gu, and P. Wang, "Effects of cyclic confining pressure on the deformation characteristics of natural soft clay," Soil Dynamics and Earthquake Engineering, vol. 78, pp. 99-109, 2015.

[12] A. Sakai, L. Samang, and N. Miura, "Partially-drained cyclic behavior and its application to the settlement of a low embankment road on silty-clay," Soils and Foundations, vol. 43, no. 1, pp. 33-46, 2003.

[13] C. Gu, J. Wang, Y. Cai, L. Sun, P. Wang, and Q. Dong, "Deformation characteristics of overconsolidated clay sheared under constant and variable confining pressure," Soils and Foundations, vol. 56, no. 3, pp. 427-439, 2016.

[14] L.-L. Li, H.-B. Dan, and L.-Z. Wang, "Undrained behavior of natural marine clay under cyclic loading," Ocean Engineering, vol. 38, no. 16, pp. 1792-1805, 2011.

[15] X. Bian, J. Jiang, W. Jin, D. Sun, W. Li, and X. Li, "Cyclic and postcyclic triaxial testing of ballast and subballast," Journal of Materials in Civil Engineering, vol. 28, no. 7, Article ID 04016032, 2016

[16] M. Tao, L. N. Mohammad, M. D. Nazzal, Z. Zhang, and Z. Wu, "Application of shakedown theory in characterizing traditional and recycled pavement base materials," Journal of Transportation Engineering, vol. 136, no. 3, pp. 214-222, 2010.

[17] R. J. Mitchell and R. D. King, "Cyclic loading of an ottawa area champlain sea clay," Canadian Geotechnical Journal, vol. 14, no. 1, pp. 52-63, 1977.

[18] L. Tang, H. Chen, H. Sang, S. Zhang, and J. Zhang, "Determination of traffic-load-influenced depths in clayey subsoil based on the shakedown concept," Soil Dynamics and Earthquake Engineering, vol. 77, pp. 182-191, 2015.

[19] T. Wichtmann and T. Triantafyllidis, "Inspection of a highcycle accumulation model for large numbers of cycles $(\mathrm{N}=2$ million)," Soil Dynamics and Earthquake Engineering, vol. 75, pp. 199-210, 2015. 